\title{
Fluoride in the Diet of Two-Year-Old Children
}

E. Angeles Martinez-Mier DDS, MSD, PhD ${ }^{1}$; Kathryn L. Spencer, DMD ${ }^{2}$; Brian J. Sanders, DDS, MS ${ }^{2}$; James E. Jones, DMD, MSD, EdD, PhD ${ }^{2}$; Armando E. Soto-Rojas, DDS, MPH ${ }^{1}$; Angela M. Tomlin, $\mathrm{PhD}^{3}$; LaQuia A. Vinson, DDS, MPH, ${ }^{2}$; James. A. Weddell, DDS, MSD ${ }^{2}$; George J. Eckert, MAS ${ }^{4}$

${ }^{1}$ Department of Cariology, Operative Dentistry and Dental Public Health, Indiana University School of Dentistry; ${ }^{2}$ Department of Pediatric Dentistry, Riley Hospital for Children, Indiana University School of Dentistry, ${ }^{3}$ Department of Child Development, Riley Hospital for Children; ${ }^{4}$ Department of Biostatistics, Indiana University School of Medicine.

Correspondence and reprints:

E. Angeles Martinez-Mier, DDS, MSD, PhD

Cariology, Operative Dentistry and Dental Public Health

Binational/Cross-Cultural Health Enhancement Center

Indiana University School of Dentistry

415 Lansing Street

Indianapolis IN 46202

esmartin@iu.edu

\section{Keywords}

Fluoride, pediatric dentistry, caries, fluorosis, diet

This is the author's manuscript of the article published in final edited form as:

Martinez-Mier, E. A., Spencer, K. L., Sanders, B. J., Jones, J. E., Soto-Rojas, A. E., Tomlin, A. M., ... Eckert, G. J. (2017). Fluoride in the diet of 2-years-old children. Community Dentistry and Oral Epidemiology, 45(3), 251-257. https://doi.org/10.1111/cdoe.12283 


\begin{abstract}
Objectives: This study aimed to calculate the fluoride concentrations of commonly consumed foods and beverages for two-year-old children utilizing market basket information for the U.S. Midwest region.
\end{abstract}

Methods: Total Diet Study food lists were cross-referenced with National Health and Nutrition Examination Survey - What We Eat in America data to determine the foods and beverages to be included. Fluoride concentrations were determined using a modification of the hexamethyldisiloxane microdiffusion technique. Fluoride concentrations were summarized for each of the food categories. Daily dietary fluoride intake was estimated using a simulation analysis.

Results: Food and beverage fluoride concentrations varied widely, ranging from nondetectable for some oils and dairy products to more than $3.0 \mu \mathrm{gF} / \mathrm{g}$ food for some processed meats, fish, and fruits. The estimated mean $( \pm \mathrm{SD})$ daily dietary fluoride intake, excluding dentifrice and supplements, was $412 \pm 114 \mu \mathrm{gF} /$ day. The estimated average ingestion for a two-year-old weighing $12.24 \mathrm{~kg}$ was $0.034 \pm 0.009 \mathrm{mg} / \mathrm{kg} / \mathrm{day}$. A diet based on foods and beverages in the fifth percentile of fluoride intake distribution for an average child would result in $247 \mu \mathrm{gF} /$ day or $0.020 \mathrm{mg} / \mathrm{kg} / \mathrm{day}$, while a diet with foods and beverages in the ninety-fifth percentile would result in a total intake of $622 \mu \mathrm{gF} / \mathrm{day}$, or $0.051 \mathrm{mg} / \mathrm{kg} /$ day.

Conclusions: The fluoride concentrations of foods and beverages varies widely and, if items in the 95th percentile of fluoride intake distribution are ingested, children could consume more fluoride than the recommended $0.05 \mathrm{mg} / \mathrm{kg} / \mathrm{day}$. Fluoride intake calculated in this study was higher than historically reported dietary levels. 
Fluoride in the diet

\section{Introduction}

Fluoride has been a major factor in the significant decrease in caries over the past few decades ${ }^{1}$. However, when developing teeth are exposed to excessively high amounts of fluoride, changes in the tooth are seen most clearly in the enamel, ${ }^{2}$. Excess fluoride can result in dental fluorosis, which generally presents clinically as opacities within the enamel. The critical time for development of enamel fluorosis of maxillary central incisors has been suggested to be during the first three years of life ${ }^{3}$.

Over the last three decades, it has been reported that the prevalence of enamel fluorosis is on the rise in the US ${ }^{4}$. Most of the observed fluorosis is very mild or mild, which is difficult to distinguish by the lay public, but there are also more cases of moderate to severe fluorosis being reported. It has been concluded that fluoride appears to be more readily available for consumption nowadays during the critical window when enamel is most susceptible to fluorosis ${ }^{4}$. A National Institute of Dental and Craniofacial Research (NIDCR) survey conducted in 1987 showed that 22\% of those aged 7 years and older had fluorosis ${ }^{4}$, while a National Health and Nutrition Examination Survey (NHANES) conducted from 1999 to 2002 showed that 32\% of those aged 6-19 had some level of fluorosis, with very few being any more severe than mild cases ${ }^{5}$.

The Environmental Protection Agency (EPA) recently conducted a review of the exposure and relative contribution of all fluoride sources, utilizing the available information. It showed that sources with the greatest contribution to total fluoride ingestion include the diet, water, and dental products ${ }^{6}$. As soon as a child begins to ingest a broader array of foods or liquids (over and above formula or breast milk alone), his/her exposure to fluoride may increase ${ }^{7}$.

Many studies have attempted to determine fluoride intake at the individual level, primarily utilizing either surveys or direct observation and measurement ${ }^{6,7}$. At the population level, a market basket approach has been suggested to be more representative of intake based on locale, since it is based on an analysis that selects a number of the most commonly bought food and beverages ${ }^{6}$. Such studies have shown that infant baby food can have differing amounts of fluoride depending on which type of food is highest in proportion in the product ${ }^{7}$. For example, chicken-based products have been reported to contain the most fluoride ${ }^{7}$. 
In younger children, water intake can be a large contributor of fluoride to the diet. It has been determined that water's contribution depends on the amount taken, the level of fluoride in the water source, and the purification method (if any) which is used ${ }^{6}$. It has been estimated that children 1-3 years of age consume on average $0.44 \mathrm{mg}$ F/day from average water ingestion if the concentration of the water they consume falls within the $90^{\text {th }}$ percentile (1.43 mg/L), as described by the Environmental Protection Agency ${ }^{6}$. Water ingestion includes direct and indirect sources; the latter include water incorporated into beverages and foods. There are other, less significant sources of fluoride in the environment. Dust and soil, for example, can contribute to a person's total fluoride intake ${ }^{6}$.

Over the years, research has pointed toward possible changes in the fluoride concentrations of specific foods and beverages and in the average total fluoride ingestion 6 . These differences have been attributed to changing detection and collection methods, as well as to changes in the foods consumed. During the past 30 years, important advances have been made in the methods used for fluoride analysis ${ }^{6,8}$. Colorimetric studies which were previously conducted have the drawback that other particles within the food can interfere with the essay. More recent studies use a fluoride-ion-specific electrode to measure fluoride levels ${ }^{6,8}$.

The primary purpose of this study was to determine fluoride concentrations in currently consumed foods and beverages in the U.S. Midwest using standardized analytical methods. The secondary aim was to pair fluoride concentration data with intake information in order to estimate how much dietary fluoride a two-year-old child could be ingesting.

\section{Methods}

Foods and beverages consumed in the U.S. Midwest region Market Basket were included in the study. Market basket studies, also called the total diet studies (TDS), are conducted by the Federal Drug Administration (FDA) in the US ${ }^{9}$. The foods and beverages collected for the TDS are representative of the major components of the average diet of the U.S. population, based on national food-consumption surveys. The total diet studies obtain foods and beverages in a table-ready form and analyze them to 
determine amounts of nutrients (analytes) and impurities. The overall intake of analytes is determined by multiplying the amount of the nutrient by the mean consumption amount of that food. In 2003, an update to the TDA food-list was completed, based on the list of the USDA's 1994-96, 1998 Continuing Survey of Food Intakes by Individuals. This survey included detailed information on the types and amounts of food and beverages consumed by its participants ${ }^{10}$. The list produced in this update has been used since 2003. Approximately 280 foods and beverages are analyzed in the current TDS. Market baskets, which are collections of the analyzed foods and beverages, are gathered once a year in each of the four regions of the United States. These regions are North Central (Midwest), Northeast, West, and South. Fluoride levels are not assessed in the total diet study; however, information about common diet components can be taken from this research ${ }^{9}$.

The TDS Food List from $2003{ }^{10}$ was cross-referenced with NHANES - What We Eat in America (WWEIA - 2003 - 2004) ${ }^{11}$ data to determine the foods and beverages to be included for the analysis for this study. WWEIA is the dietary interview component of NHANES and lists 358 foods. Each dataset provided different types of information needed for the current study. The TDA provided a lists of foods and beverages specific for the U.S. Midwest by age and group with consumption amounts, while WWEIA provided information about foods eaten in combination, by occasion, and the source of foods (home or not). It is conducted as a partnership between the U.S. Department of Agriculture (USDA) and the U.S. Department of Health and Human Services (DHHS). Data are released every two years. The most recent data release was 2009-2010. NHANES data on consumption produces a list of foods/beverages most often consumed by various age groups in specific regions of the U.S. NHANES reports on foods/beverages so that a typical diet can be constructed. These are reported in the WWEIA databases ${ }^{11}$. We obtained the specific lists for the Male/Female two years old subgroup, which is one cohort that would be more susceptible to developing enamel fluorosis in teeth which are most visible and could present an esthetic problem and for which the information would be most relevant ${ }^{3}$. Comparing the WWEIA and TDS food lists showed that 117 foods and beverages were present in both lists. These foods and beverages, classified into 10 categories (Beverage, Dairy, Egg, Fat/Oil, Fruit, Grain, 
Legume, Mixture, Meat/Protein/Fish, Sweets, and Vegetable), represent the most frequently consumed foods and beverages for our target age group in the Midwest. A complete list is provided in the supplemental material for this article.

Using georeferenced grocery store data from the Marion County Public Health Department, 861 grocery stores were located in Marion County, IN and included in determining locations for food and beverage collection. Marion County is consolidated with the city of Indianapolis, IN. Store criteria were: a chain with multiple stores in the Midwest or nationally; a website containing food and beverage information (used to check the availability of products); and the ability to be spatially joined to a unique Census tract. These stipulations were used to determine whether a store chain was likely to sell the desired 117 items and could be associated with the demographic characteristics of the surrounding population. We intended to match the demographic characteristics of the NHANES participants who answered the surveys that were used to construct the food lists. One hundred sixty four stores from 15 chains met these requirements. There were 112 Census tracts in the county with at least one collection store location and residents' demographic characteristics that closely aligned with those of participants in NHANES 2009 - 2010 (the most recent dataset. released). We identified the Census tracts where residents' demographics most closely aligned with the demographic characteristics of participants in NHANES by calculating the root-mean-square-deviation (RMSD) based on Jenks breaks ${ }^{12}$ between the NHANES participants' household income and each Census tract population's household income, to identify Census tracts with low RMSD (Figure 1). From those, subsets were selected and Chi-squared distributions were calculated for each demographic category (Gender, Age, Race, and Family Income) to determine goodness of fit between this subset of Census tracts and the NHANES survey participants. Three grocery stores with the best goodness of fit were finally selected from that subset with the best goodness of fit results, including a discount supermarket chain, a large supermarket chain, and a discount regional chain variety store. Table 1 provides a comparison of the demographic characteristics of NHANES 2009-2010 participants and the residents of the Census tracts corresponding to the three collection stores selected.

A set of foods and beverages was then purchased at each of the selected three locations. If the store brand was available, this was purchased because it tended to be the 
more inexpensive option. Every purchase made was of the exact sample as it was written. For example, the fruit juice samples were natural juices with sugar, not a sugarfree or reduced sugar juice option. No attempt was made to purchase an organic product over a non-organic product. We attempted to obtain one sample of each item from the three different locations. One hundred thirteen foods were collected at one store, 76 items were obtained at a second one, and 115 samples were collected at a third store. A total of 291 samples were collected. There were at least two samples per item, with 57 items having three. Items were not obtained if they were not available in stock at the location on the collection date. No duplicate items were purchased.

Once food and beverage products were obtained, the samples were taken to the Oral Health Research Institute at Indiana University School of Dentistry. The samples were prepared for analysis following FDA guides, which include preparation of all items with distilled (fluoride-free) water ${ }^{13,14}$. A standard commercial-grade blender was used to homogenize the samples for approximately two minutes. Deionized water was added as needed to allow for complete homogenization. Initial and final weights of the sample homogenates were recorded and taken into account when calculating final fluoride concentrations for the samples. Samples were frozen until the time of the analysis. Not all homogenates are easily pipetted; thus food and beverage samples were analyzed based on weight. Approximately 1.0 gram of each homogenate was used for fluoride analysis.

Fluoride level determination for food and beverage aliquots was conducted using a modification of the hexamethyldisiloxane (HMDS, Sigma Chemical Co., St Louis, MO, USA) micro-diffusion procedure of Taves, ${ }^{15}$ as modified by Martinez Mier et al. ${ }^{8}$. A measured and recorded weight of each sample (approximately $1.0 \mathrm{~g}$ ) was dispensed into Petri dishes (Falcon 15 cm plastic Petri dishes, Fisher Scientific Co./Falcon); a sodium hydroxide (NaOH, A.R. Sigma Chemical Co.) trap solution was loaded onto the Petri dish lid and after adding sulfuric acid $\left(\mathrm{H}_{2} \mathrm{SO}_{4}\right.$, Sigma Chemical Co.) saturated with HMDS, each dish was immediately tightly sealed. As the diffusion process occurred overnight, fluoride was released by acid hydrolysis and trapped in the $\mathrm{NaOH}$ trap. The fluoride-containing trap was then removed and buffered to $\mathrm{pH} 5.2$ with perchloric acid $\left(\mathrm{HClO}_{4}\right.$, Sigma Chemical Co.). The resulting solution was adjusted to a final volume of $100 \mu \mathrm{l}$ with Total Ionic Strength Buffer (TISAB II, Fisher Scientific Co.). Sets of 
approximately 30 samples were analyzed at any one time. Fluoride levels were determined by comparing the millivolt reading of each sample to standard curves, covering the range of the samples' values, prepared from the data for standard solutions of diffused fluoride determined at the time the samples were analyzed. The precision and validity of the analysis technique has been reported elsewhere ${ }^{10}$.

Before the samples were analyzed, three investigators were trained and calibrated in the conduct of these fluoride analysis methods until an intra- and inter-analyst correlation coefficient (ICC) higher than 0.90 (indicating excellent repeatability) was achieved. The estimated fluoride concentrations of the foods and beverages were combined with the ingestion information to calculate estimated fluoride intake ${ }^{10,11}$. Fluoride per gram of food was calculated for each of the food categories using all foods within each category. Daily mean and percentile total fluoride intake were estimated using a simulation analysis of the typical diet for a healthy two-year-old, as reported in WWEIA $^{11}$. The simulation involved randomly generating 10,000 days of a typical diet. This simulation approach allowed us to randomly select products within food categories with varied fluoride intake. Both WWEIA and TDA datasets report amount of foods consumed by grams daily and WWEIA reports records per day for each survey participant. However, the variables that are included in these datasets did not allow us to create a simulation that randomly combined different foods and beverages within the categories. For that reason, we elected to use food servings. The daily food servings for a typical diet for a healthy two-year-old were: 4 milk, 2 juice, 1 dairy (e.g. cheese, yogurt, etc.), 1 sweet treat (e.g. cookie, cake, etc.), 1 snack (e.g. popcorn, pretzels, etc.), 1 fruit, 2 vegetables, 1 pasta/rice/potato, 2 bread, 2 meat, 1 cereal or egg, 1 condiment (e.g. butter, jelly, salsa, etc.). There was no variation in the number of servings or the serving sizes. The variation was in the foods selected for each day of the simulation. With the wide variety of foods available within each of the food categories, it was considered that this would adequately represent the variation in fluoride ingestion. The serving sizes depended on the specific foods and were based on the information on the food labels, and the intake datasets. The individual foods were placed in one of the serving categories. Mixed foods were assigned to multiple categories based on WWEIA information, as appropriate; for example, a hamburger is a meat and a bread serving. Most information is 
for an 'adult' serving, which was converted to a child serving as appropriate. For example, an adult serving of dry cereal is usually 1 cup; the child serving was $1 / 2$ cup, so the number of grams was multiplied by 0.5. However, for eggs, the serving size was kept as one egg. The serving size information was combined with the fluoride per gram of food to calculate the amount of fluoride in one serving of each food. For the simulated diet, selection of cereal or an egg at breakfast was done randomly, with a 50/50 chance of each choice. Selections of a mixed food or individual foods at lunch and at dinner were similarly randomized. For each simulated day, foods were randomly selected within each category and the mean and percentile total fluoride intake were calculated.

\section{Results}

One hundred seventeen foods and beverages were selected for inclusion in the study. These were selected based on the Total Diet Study (TDS) Food Lists ${ }^{10}$ which were cross-referenced with NHANES - WWEIA data ${ }^{13}$. Data on the food and beverage distributions of fluoride concentrations are presented in Tables 2 and 3.

Food and beverage's fluoride concentrations varied widely, ranging from nondetectable for some products to more than $3.0 \mu \mathrm{gF} / \mathrm{g}$ food for some processed meats and fish, vegetables, and fruit. Some dairy and grain samples had concentrations higher than $2.0 \mu \mathrm{gF} / \mathrm{g}$. Some relatively low mean fluoride items include sweets at $0.20 \mu \mathrm{F} / \mathrm{g}$, vegetables at $0.34 \mu \mathrm{F} / \mathrm{g}$, and beverages at $0.33 \mu \mathrm{F} / \mathrm{g}$. High fluoride groups include grains at $0.73 \mu \mathrm{F} / \mathrm{g}$ and 'mixture' category at $0.62 \mu \mathrm{F} / \mathrm{g}$. Dairy, egg, fats and oils, fruits and grains all had some items with fluoride levels so low that they could not be detected.

To account for the variability in the fluoride levels for each category, we simulated the daily fluoride intake amount as described above. From the simulated days, we estimated the means, standard deviation, standard error, range, and 95\% confidence interval for fluoride intake. The estimated mean $( \pm S D)$ daily dietary fluoride intake was $412 \pm 114 \mu \mathrm{gF} / \mathrm{day}$, with 5th and 95th percentiles at $247 \mu \mathrm{gF} / \mathrm{day}$ and $622 \mu \mathrm{gF} / \mathrm{day}$, respectively. A two-year-old male in the $50^{\text {th }}$ weight-for-age percentile $(12.24 \mathrm{~kg})$ would ingest a mean $0.034 \pm 0.009 \mathrm{mg} / \mathrm{kg} /$ day, with a median of $0.032 \mathrm{mg} / \mathrm{kg} /$ day. This same child ingesting a diet based on foods and beverages in the $5^{\text {th }}$ percentile of fluoride intake distribution would consume a mean of $0.02 \mathrm{mg} / \mathrm{kg} / \mathrm{day}$. A diet in the 95th percentile for 
fluoride intake distribution would result in a mean total intake of $0.051 \mathrm{mg} / \mathrm{kg} /$ day. A two-year-old male in the $95^{\text {th }}$ weight-for-age percentile $(14.45 \mathrm{~kg})$ would ingest a mean $0.028 \pm 0.008 \mathrm{mg} / \mathrm{kg} /$ day if consuming foods and beverages with average fluoride concentrations. A two-year-old male in the $5^{\text {th }}$ weight-for-age percentile $(10 \mathrm{~kg})$ would ingest a mean of $0.041 \pm 0.011 \mathrm{mg} / \mathrm{kg} /$ day. These values would be $0.036 \pm 0.01$ $\mathrm{mg} / \mathrm{kg} /$ day, $0.029 \pm 0.008 \mathrm{mg} / \mathrm{kg} /$ day, and $0.045 \pm 0.012 \mathrm{mg} / \mathrm{kg} /$ day, respectively, for girls in the $50^{\text {th }}, 95^{\text {th }}$ and $5^{\text {th }}$ weight-for-age percentiles. All of the values described above correspond to dietary fluoride intake alone, and exclude any of other potential sources of fluoride exposure.

\section{Discussion}

Our findings show that the fluoride concentrations of foods and beverages varies widely in the U.S. Midwest. Comparisons to previous reports need to be made cautiously in light of changes over the years in fluoride determination methods, sample selection and collection methods, and food preferences, as well as differences in the age of participants. Few data exist on dietary fluoride intake on the target population of 2-year-old children. Furthermore, previous studies have employed various dietary analysis methods, such as market baskets, dietary records, duplicate plates and others.

Ophaug et al. reported in 1980 that mean total fluoride intake for a two-year-old child in the North Central (Midwest) region was $0.049 \mathrm{mg} / \mathrm{kg} /$ day $(0.610 \mathrm{mg} /$ day when diet was analyzed using market baskets from 1977 and 1978) ${ }^{16}$. Their study followed the 1977 or 1978 toddler TDS food collections made by the FDA in representative cities from the South (Orlando, Florida), North East (Philadelphia, Pennsylvania), North Central (Grand Rapids, Michigan) and West (Los Angeles, California) Dietary Regions of the United States. When water contribution to overall intake is subtracted from these findings, the average child was ingesting $0.308 \mathrm{mg} / \mathrm{day}$ and $0.025 \mathrm{mg} / \mathrm{kg} / \mathrm{day}$ from foods and beverages other than water ${ }^{17}$. Our findings show that two-year-old children consuming a mean of $0.412 \mathrm{mg} /$ day or $0.034 \mathrm{mg} / \mathrm{kg} /$ day, are ingesting relatively $30 \%$ more than these reported historic values. Additional studies were published in 1985 by this group of investigators to show that $0.046 \mathrm{mg} / \mathrm{kg} /$ day, $0.542 \mathrm{mg} /$ day was ingested by two-year-old children in the Midwest from water and food ${ }^{18}$. Values from the 1985 
market basket study are not easily compared to our findings because contribution from foods and beverages other than water is not listed, and so the contribution of water alone cannot be subtracted from the overall fluoride intake values. Individual food and beverage value comparisons were also not possible, since Ophaug and colleagues did not report them.

Finally, a duplicate plate study in Indianapolis reported that children with an average age of 28 months consumed $0.965 \mathrm{mg} /$ day when fluoride intake from foods, beverages, and dentifrice was analyzed ${ }^{19}$. Foods and beverages contributed an average of $0.542 \mathrm{mg} /$ day (56.2\%) of this intake. However, these data are not easily compared to ours because the Indianapolis study does not report the contribution from foods and beverages other than water ${ }^{19}$.

The limitations of our study include the fact that we did not obtain duplicate samples for individual items within a single store. We also did not include different flavors and brands, as well as product lots. This may have prevented us from determining within-sample variation. However, we managed to obtain at least two samples per item, with 57 items having three samples from different stores. Other limitations include the lack of information about the actual brands, flavors, lots and sizes that were ingested by our target population. Finally, our data do not allow for the determination of the relative contribution from foods and beverages, since water intake was not included in our simulations; this means that comparisons to some other studies are limited.

This study precisely determined fluoride concentrations of currently consumed foods and beverages, and allowed us to report how they vary widely. We can therefore conclude that the daily intake for two-year-old children will depend on the foods typically consumed by each child based on his/her choice of foods and beverages. If the combination of foods and beverages typically consumed falls within the 95th percentile of highest fluoride intake distribution, children will most likely consume larger amounts of fluoride than the $0.05 \mathrm{mg} / \mathrm{kg} /$ day generally discussed as optimal. Intake above this 0.05 $\mathrm{mg} / \mathrm{kg} /$ day threshold may result in elevated risk of fluorosis ${ }^{20}$.

When comparing previously reported values for dietary fluoride intake to current values of dietary fluoride intake, it can be easily observed that there are many differences. These can be attributed not only to differences in the fluoride detection methods 
employed by current and past studies but also to changes in food preferences over the years. If the prevalence mild fluorosis continues to rise in certain age groups as previously reported ${ }^{4,5}$, there is a definite need to obtain precise and valid measurements of fluoride concentrations of currently consumed foods and beverages in order to aid in the ongoing monitoring of exposure in children. Future studies should expand on our work by collecting additional data from the Midwest and other regions in the United States. 
Fluoride in the diet

\section{Acknowledgements}

This research was made possible by a grant from Delta Dental Foundation, associated with Delta Dental of Indiana, Michigan, and Ohio and the assistance of the IUPUI Polis Center in geoinformatics. 


\section{References}

1. Petersson GH, Bratthall D. The caries decline: a review of reviews. Eur J Oral Sci 1996; 104: 436-43.

2. Robinson C, Connell S, Kirkham J, Brookes SJ, Shore RC, Smith AM. The effect of fluoride on the developing tooth. Caries Res 2004; 38: 268-76.

3. Buzalaf MA, Levy SM. Fluoride intake of children: considerations for dental caries and dental fluorosis. Monogr Oral Sci 2011; 22: 1-19.

4. Rozier RG. The prevalence and severity of enamel fluorosis in North American children. J Public Health Dent 1999; 59: 239-46.

5. Beltrán-Aguilar ED, Barker LK, Canto MT, Dye BA, Gooch BF, Griffin SO, et al. Surveillance for dental caries, dental sealants, tooth retention, edentulism, and enamel fluorosis -- United States, 1988-1994 and 1999-2002. MMWR Surveill Summ 2005; 54: $1-43$.

6. Donohue JM, Duke T, Opresko D, Watson A, Tomkins B. Fluoride: Exposure and relative source contribution analysis. Washington, DC: U.S. Environmental Protection Agency U.S. Environmental Protection Agency; Report No: 820-R-10015; 2010.

7. Heilman, JR, Kiritsy MC, Levy SM, Wefel JS. Fluoride concentrations of infant foods. J Amer Dent Assoc 1997; 128: 857-63.

8. Martinez-Mier EA, Cury JA, Heilman JR, Katz BP, Levy SM, Li Y, et al. Development of gold standard ion-selective electrode-based methods for fluoride analysis. Caries Res 2010; 45: 3-12.

9. Total Diet Study Study Design. FDA; 2009 [cited 2016 August 28]. Available from: http://www.fda.gov/Food/FoodScienceResearch/TotalDietStudy/ucm184232.h tm

10. Total Diet Study food lists and consumption amounts; 2003 [cited 2016 August 28]. Available from: http://www.fda.gov/Food/FoodScienceResearch/TotalDietStudy/ucm184232.h tm

11. U.S. Department of Agriculture, Agricultural Research Service, Beltsville Human Nutrition Research Center, Food Surveys Research Group: Beltsville, MD; and U.S. 
Department of Health and Human Services, Centers for Disease Control and Prevention, National Center for Health Statistics: Hyattsville, MD. What We Eat in America, NHANES 2003-2004. [cited 2016 August 28]. Available from: http://www.cdc.gov.

12. Jenks, GF. The Data Model Concept in Statistical Mapping. International Yearbook of Cartography 1967; 7: 186-90.

13. Oakes G. Total diet study sample preparation. U.S. Food and Drug Administration; Report No.: KAN-LAB.152 version 1.5; 2006

14. Oakes G. Total Diet Sample Recipes. U.S. Food and Drug Administration; Report No.:KAN-LAB.161; 2006.

15. Taves DR. Separation of fluoride by rapid diffusion using hexamethyldisiloxane. Talant. 1968; 15: 969-74.

16. Ophaug RH, Singer L, Harland BF. Estimated fluoride intake of average two year-old children in four dietary regions of the United States. J Dent Res 1980; 59: 777-81.

17. Ophaug RH, Singer L, Harland BF. Dietary fluoride intake of 6-month and 2-year old children in four dietary regions of the United States. Am J Clin Nutrit 1985; 42: 7017.

18. Rojas-Sanchez F, Kelly SA, Drake KM, Eckert GJ, Stookey GK, Dunipace AJ. Fluoride intake from foods, beverages and dentifrice by young children in communities with negligibly and optimally fluoridated water: a pilot study. Community Dent Oral Epidemiol 1999; 27: 288-97.

19. Dietary Reference Intakes for Calcium, Phosphorus, Magnesium, Vitamin D, and Fluoride [Internet]. Washington, DC: National Academies Press; 1997. [cited 2013 May 5]. Available from: http://www.ncbi.nlm.nih.gov/books/NBK109825

20. Jenks, GF. The Data Model Concept in Statistical Mapping. International Yearbook of Cartography 1967; 7: 186-90. 


\section{List of all figure and table captions}

1. Table 1: Demographic characteristics from residents of the census tracts corresponding to collection stores Table 2: Fluoride concentrations by food and beverages categories

2. Table 3: Fluoride concentrations of selected items by food and beverages categories

3. Figure 1: Marion County map of root-mean-square deviation and color-coded ascending RMSD between NHANES respondents and Census tract household income 


\section{Tables}

Table 1: Demographic characteristics from residents of the census tracts corresponding to collection stores

\begin{tabular}{|c|c|c|c|c|c|c|}
\hline & \multicolumn{2}{|c|}{$\begin{array}{l}\text { Store } 1 \\
\text { (Near North } \\
\text { side discount } \\
\text { supermarket } \\
\text { chain) }\end{array}$} & \multicolumn{2}{|c|}{$\begin{array}{l}\text { Store } 2 \\
\text { (West side } \\
\text { large } \\
\text { supermarket } \\
\text { chain) }\end{array}$} & \multicolumn{2}{|c|}{$\begin{array}{l}\text { Store } 3 \\
\text { (East side } \\
\text { regional } \\
\text { chain variety } \\
\text { store) }\end{array}$} \\
\hline & n & $(\%)$ & $\mathbf{n}$ & $(\%)$ & $\mathbf{n}$ & $(\%)$ \\
\hline \multicolumn{7}{|l|}{ Gender } \\
\hline Male & 1750 & $(46.6)$ & 1740 & $(47.6)$ & 3824 & (51.1) \\
\hline Female & 2005 & (53.4) & 1916 & $(52.4)$ & 3664 & $(48.9)$ \\
\hline \multicolumn{7}{|l|}{ Age } \\
\hline 0 to 79 & 3654 & $(90.4)$ & 3435 & $(96.4)$ & 7358 & (98.3) \\
\hline 80 and Over & 387 & $(10.3)$ & 130 & $(3.6)$ & 130 & $(1.7)$ \\
\hline \multicolumn{7}{|l|}{ Race and Ethnicity } \\
\hline Mexican American & 233 & $(6.2)$ & 211 & $(5.8)$ & 2518 & (33.6) \\
\hline Other Hispanic & 54 & $(1.4)$ & 110 & $(3.0)$ & 799 & (10.7) \\
\hline Non-Hispanic White & 1473 & (39.2) & 2066 & $(56.5)$ & 1583 & $(21.1)$ \\
\hline Non-Hispanic Black & 1843 & $(49.1)$ & 1109 & $(30.3)$ & 2252 & $(30.1)$ \\
\hline Other Race & 152 & $(4.0)$ & 160 & $(4.4)$ & 336 & $(4.5)$ \\
\hline \multicolumn{7}{|l|}{ Family Income } \\
\hline$\$ 0$ to $\$ 24,999$ & 242 & $(27.9)$ & 244 & $(25.4)$ & 653 & $(37.6)$ \\
\hline$\$ 25,000$ to $\$ 44,999$ & 364 & $(42.0)$ & 306 & (31.9) & 492 & (28.3) \\
\hline$\$ 45,000$ to $\$ 74,999$ & 193 & (22.3) & 167 & $(17.4)$ & 260 & $(15.0)$ \\
\hline$\$ 75,000$ and Over & 68 & $(7.8)$ & 243 & (25.3) & 334 & (19.2) \\
\hline
\end{tabular}


Table 2: Fluoride concentrations by food and beverage categories

\begin{tabular}{|c|c|c|c|c|c|c|c|c|c|c|c|c|}
\hline Category & $\begin{array}{c}\text { Mean } \\
\mu g F / g(N)\end{array}$ & $\begin{array}{c}\text { Median } \\
\mu g F / g \\
\text { (Skewness) }\end{array}$ & SD & Min & $\begin{array}{c}5^{\text {th }} \\
\text { Percentile }\end{array}$ & $\begin{array}{c}10^{\text {th }} \\
\text { Percentile }\end{array}$ & $\begin{array}{c}2^{\text {th }} \\
\text { Percentile }\end{array}$ & $\begin{array}{c}50^{\text {th }} \\
\text { Percentile }\end{array}$ & $\begin{array}{c}7^{\text {th }} \\
\text { Percentile }\end{array}$ & $\begin{array}{c}9^{\text {th }} \\
\text { Percentile }\end{array}$ & $\begin{array}{c}\text { 95 }^{\text {th }} \\
\text { Percentile }\end{array}$ & Max \\
\hline Beverage & $0.33(4)$ & 0.07 (1.39) & 0.35 & ND & 0.01 & 0.01 & 0.06 & 0.27 & 0.61 & 0.78 & 0.78 & 0.78 \\
\hline Dairy & $0.32(30)$ & $0.14(2.63)$ & 0.48 & ND & ND & 0.02 & 0.04 & 0.14 & 0.36 & 0.90 & 1.53 & 2.06 \\
\hline Egg & ND (3) & ND (1.73) & 0.01 & ND & ND & ND & ND & ND & 0.01 & 0.01 & 0.01 & 0.01 \\
\hline Fat/Oil & $0.11(12)$ & $0.02(0.63)$ & 0.13 & ND & ND & ND & ND & 0.02 & 0.22 & 0.27 & 0.33 & 0.33 \\
\hline Fruit & 0.48 (44) & 0.10 (3.55) & 1.08 & ND & ND & ND & 0.02 & 0.09 & 0.44 & 1.00 & 3.33 & 5.26 \\
\hline Grain & $0.73(51)$ & $0.65(0.56)$ & 0.59 & ND & ND & 0.11 & 0.23 & 0.59 & 1.17 & 1.58 & 1.77 & 2.60 \\
\hline Legume & $0.45(6)$ & $0.32(0.56)$ & 0.45 & 0.01 & 0.01 & 0.01 & 0.06 & 0.32 & 0.89 & 1.08 & 1.08 & 1.08 \\
\hline Mixture & $0.62(50)$ & $0.54(0.62)$ & 0.33 & 0.11 & 0.12 & 0.25 & 0.35 & 0.59 & 0.85 & 1.05 & 1.24 & 1.55 \\
\hline MPF & $0.72(41)$ & 0.47 (2.49) & 0.72 & 0.13 & 0.14 & 0.16 & 0.26 & 0.49 & 0.88 & 1.48 & 1.66 & 3.36 \\
\hline Sweets & $0.20(3)$ & $0.19(0.48)$ & 0.09 & 0.11 & 0.11 & 0.11 & 0.11 & 0.19 & 0.30 & 0.30 & 0.30 & 0.30 \\
\hline Vegetable & $0.34(47)$ & 0.07 (3.76) & 0.65 & ND & ND & ND & 0.03 & 0.11 & 0.33 & 0.87 & 1.23 & 3.78 \\
\hline
\end{tabular}

$\mathrm{MPF}=$ Meat/Protein/Fish

$\mathrm{ND}=$ Not detectable 
Table 3: Fluoride concentrations of selected items by food and beverage categories

\begin{tabular}{|c|c|c|c|c|}
\hline Category & Lowest concentration item & $\mu g F / g$ & Highest concentration item & $\mu g F / g$ \\
\hline & Generic brand, frozen lemonade, & & & \\
\hline Beverage & concentrate & ND & Brand name, ice cherry popsicle & 0.78 \\
\hline \multirow[t]{2}{*}{ Dairy } & Generic brank, vitamin D milk & ND & Generic brand, mild cheddar cheese & 2.06 \\
\hline & & & Brand name, Scrambled eggs, prepared & \\
\hline Egg & Scrambled eggs, pre-prepared & ND & from scratch & 0.01 \\
\hline Fat/Oil & Gourmet brand, vegetable oil & ND & Brand name, buttermilk ranch dressing & 0.33 \\
\hline Fruit & Brand name, canned cling peaches & ND & Brand name, raisings & 5.26 \\
\hline Grain & Brand name, long grain enriched rice & ND & Brand name, saltine crackers & 2.60 \\
\hline Legume & Generic brand, creamy peanut butter & 0.01 & Gourmet brand, creamy peanut butter & 1.08 \\
\hline Mixture & Brand name, condensed tomato soup & 0.11 & Brand name, beef cheese taco & 1.55 \\
\hline MPF & Generic brand ground beef & 0.13 & Brand name, chicken/pork franks & 3.36 \\
\hline Sweets & Brand name, nougat candy bar & 0.11 & Brand name, nougat candy bar & 0.30 \\
\hline Vegetable & Brand name, mature raw onion & ND & Generic brand, plain wavy potato chips & 3.78 \\
\hline
\end{tabular}

MPF $=$ Meat/Protein/Fish

$\mathrm{ND}=$ Not detectable 


\section{Figures}

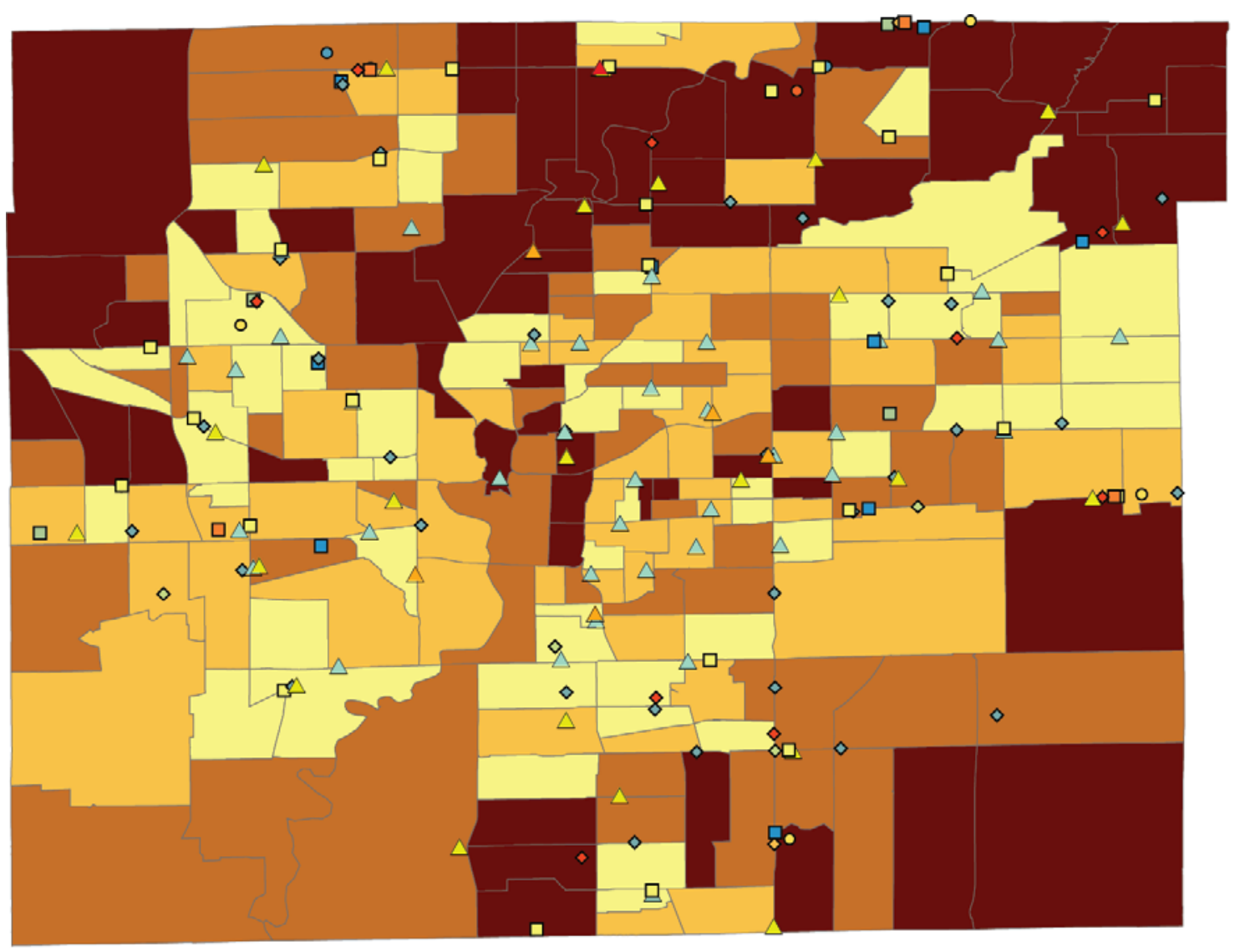

\begin{tabular}{lll}
\hline & & \\
\hline & &
\end{tabular}
6

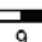

${ }_{12}^{\text {Miles }}$

\section{Legend}

Chain stores $(n=164)$

ALDI

- Costco

• Dollar General

$\triangle$ Family Dollar

․ Gordon Food Service

$\diamond$ Kmart

$\triangle$ Kroger

․ Marsh

- Meijer

$\diamond \quad$ Menards

$\triangle$ Safeway

- Sam's Club

- Trader Joe's

• Walmart

A Whole Foods

Family income, RMSD by census tract $(n=224)$

$\square 0.094786-0.174232$

$0.174233-0.225645$

$0.225646-0.282840$

$0.282841-0.681091$

Figure 1: Marion County map of root-mean-square deviation and color-coded ascending RMSD based on Jenks breaks, between

NHANES respondents and Census tract household income 


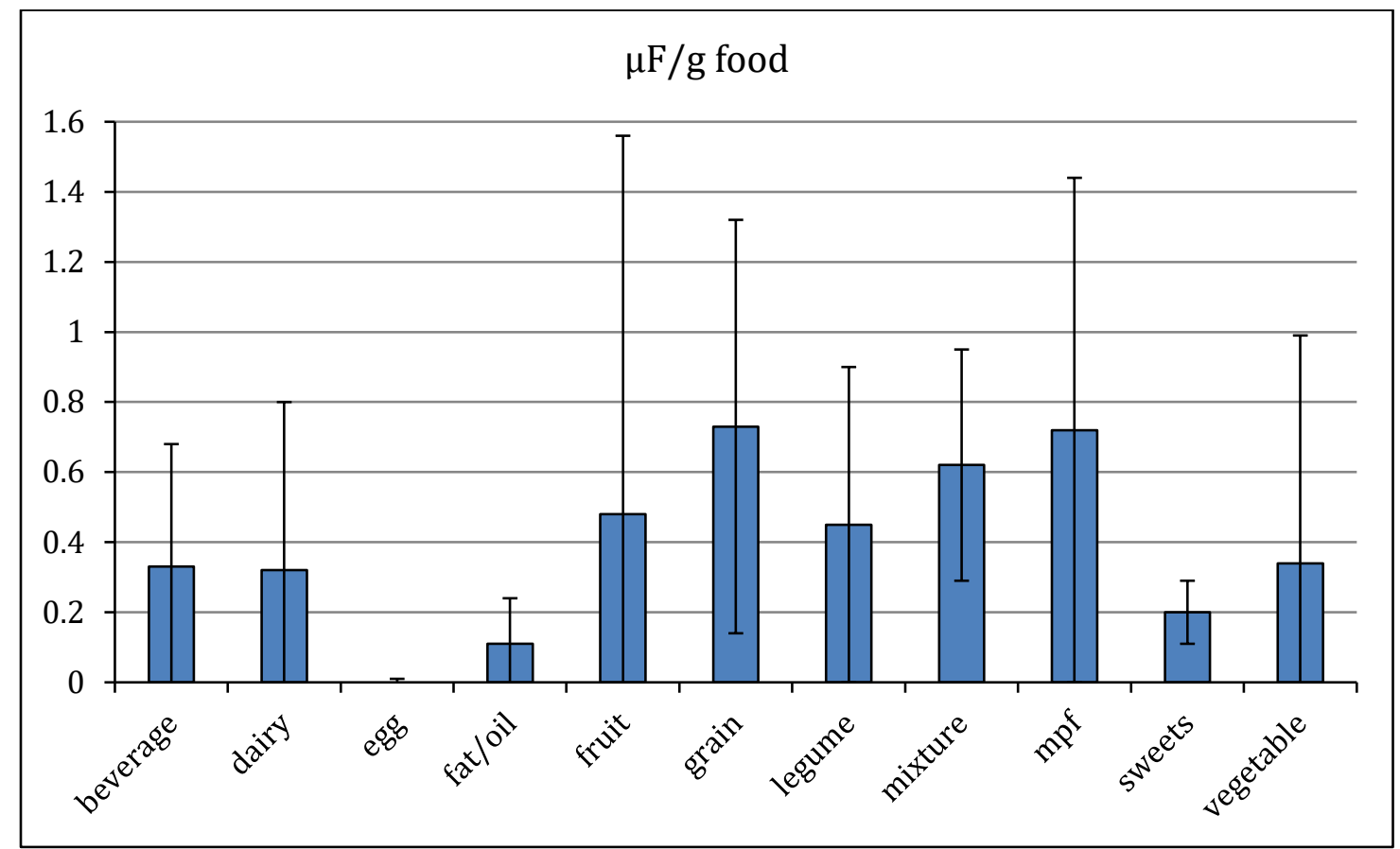

Figure 2: Fluoride content (mean +/- SD) in food and beverage categories $\mathrm{MPF}=\mathrm{Meat} /$ protein/fish 